\title{
Ultrasound bone densitometry and dual energy $X$-ray absorptiometry in patients with spinal cord injury: a cross-sectional study
}

\author{
YW Chow ${ }^{1}$, C Inman ${ }^{2}$, P Pollintine ${ }^{1}$, CA Sharp ${ }^{1}$, MJ Haddaway ${ }^{1}$, W El Masry ${ }^{2}$ and MWJ Davie ${ }^{1}$ \\ ${ }^{1}$ Charles Salt Research Centre, ${ }^{2}$ Midlands Centre for Spinal Injuries, Robert Jones and Agnes Hunt Orthopaedic and \\ District Hospital NHS Trust, Oswestry, Shropshire SY10 7AG, UK
}

Bone is lost following spinal cord injury (SCI) and in the long-term may become osteopenic and liable to fracture. Two non-invasive techniques, ultrasound bone densitometry (USBD) and dual energy X-ray absorptiometry (DXA), have been applied to monitor bone changes after spinal injury. 31 SCI patients were scanned using an ultrasound bone densitometer, to give measurements of speed of sound (SOS), broadband ultrasound attenuation (BUA) and 'stiffness'. The time since injury of these patients ranged between 5 weeks to 36 years with a mean of $5.87 \pm 10.21$ years. Ultrasonic properties at the calcaneus of these patients were significantly lower than the healthy reference population, and a rapid decline in ultrasound properties occurred in the first 3 months. The fall continued up to 54 months but at a slower rate. The normal linear relationship between SOS and BUA was not altered by SCI. Eighteen patients had DXA measurements at the lumbar spine and the right proximal femur. Bone mineral density (BMD) at the femoral neck was significantly lower than the normal reference population $(P<0.05)$. SOS and 'stiffness' correlated significantly with BMD at the lumbar spine, Ward's triangle, the femoral neck, the greater trochanter and the intertrochanteric site $(P<0.05)$. BUA correlated significantly at all these sites with the exception of the trochanter. A negative correlation was found between the ultrasonic properties at the calcaneus and BMD at the lumbar spine which is in contrast to the positive relationship in normal subjects. There was a tendency for BMD to increase at the lumbar spine after the first 12 months after injury, although this trend was not significant overall. The 'stiffness' at the calcaneus and BMD at the femoral neck were lower than the reference population following 12 months since injury. These results show that bone deficit at the calcaneus occurs rapidly and to a severe degree after SCI, and that ultrasound has an important role to play in the assessment of bone status in these patients.

Keywords: spinal cord injury; ultrasound; dual energy X-ray absorptiometry; bone mineral density; speed of sound; broadband ultrasound attenuation

\section{Introduction}

Following spinal cord injury calcium is rapidly mobilised from the skeleton leading to hypercalciuria, increased urinary excretion of hydroxyproline and a subsequent loss of bone leading to osteopenia. ${ }^{1,2}$ However, this skeletal loss is not uniform, and differential removal has been reported between the lumbar spine, the proximal femur and the tibia, ${ }^{3}$ and between the distal femur and proximal tibia. ${ }^{4}$ An incidence of $5 \%$ has been reported for fractures encompassing these regions of the lower limb after $\mathrm{SCI}^{5}$ and of these only $46 \%$ were sustained from nontrivial injuries.

The possibility that there may be differential bone loss over other areas in the lower limb has not been systematically evaluated.

Correspondence: YW Chow, PhD
Dual energy X-ray absorptiometry (DXA) has been used to establish the changes in bone mineral composition, allowing quantification of BMD $\left(\mathrm{g} / \mathrm{cm}^{2}\right)$ and bone mineral content, $\mathrm{BMC}(\mathrm{g})$, at specific sites of the body particularly the upper end of the femur and the lumbar spine. ${ }^{6}$ However its use in following changes in bone mineral in SCI patients in their acute period of injury is limited since SCI patients have a restricted mobility.

Recent developments in technology have seen the introduction of the commercial ultrasound bone densitometer (USBD) which measures the speed of sound (SOS) and broadband ultrasound attenuation (BUA) at the calcaneus. ${ }^{7}$ SOS is defined as the transit time of the ultrasound wave as it passes through the calcaneus. BUA measures the reduction in the intensity of individual frequency components of the wave as they pass through the heel region and is 
Table 1 Details of the 31 SCI patients investigated

\begin{tabular}{|c|c|c|c|c|c|}
\hline $\operatorname{Sex}$ & $\begin{array}{l}\text { Age } \\
(y r)\end{array}$ & $\begin{array}{l}\text { Time since } \\
\text { injury }(y r)\end{array}$ & $\begin{array}{c}\text { Examinations } \\
\text { taken }\end{array}$ & $\begin{array}{c}\text { Level of } \\
\text { injury }\end{array}$ & Frankel \\
\hline$F(R)$ & 19 & 0.21 & US \& DXA & L3 & $\mathrm{D}$ \\
\hline$F(R)$ & 20 & 0.29 & US \& DXA & T6 & A \\
\hline$F(R)$ & 23 & 2.28 & US & L1 & $D^{*}$ \\
\hline$F(R)$ & 25 & 0.30 & US \& DXA & $\mathrm{T} 10$ & A \\
\hline$F(R)$ & 33 & 0.22 & US \& DXA & T5 & A \\
\hline$F(R)$ & 38 & 2.02 & US \& DXA & L1 & $\mathrm{D}$ \\
\hline$F(R)$ & 43 & 13.64 & US \& DXA & $\mathrm{T} 11$ & $A^{*}$ \\
\hline $\mathrm{F}(\mathrm{H})$ & 45 & 0.19 & US & T5 & A \\
\hline$F(\mathrm{H})$ & 49 & 33.7 & US & T12 & B \\
\hline$F(R)$ & 49 & 0.14 & US \& DXA & L3 & $\mathrm{C}$ \\
\hline $\mathrm{F}(\mathrm{P})$ & 58 & 0.36 & US & $\mathrm{T} 12$ & A \\
\hline$F(P)$ & 60 & 2.28 & US & T9 & $\mathrm{C}$ \\
\hline M & 19 & 0.20 & US \& DXA & $\mathrm{C} 7$ & $\mathrm{D}$ \\
\hline M & 19 & 0.25 & US \& DXA & $\mathrm{C} 5$ & A \\
\hline M & 19 & 0.18 & US & $\mathrm{C} 5$ & A \\
\hline M & 22 & 0.15 & US \& DXA & C6 & $\mathrm{D}$ \\
\hline M & 25 & 0.22 & US \& DXA & $\mathrm{C} 5$ & $\mathrm{E}$ \\
\hline M & 25 & 0.23 & US \& DXA & $\mathrm{C} 2$ & $\mathrm{E}$ \\
\hline $\mathbf{M}$ & 27 & 0.26 & US \& DXA & $\mathrm{T} 12$ & $\mathrm{D}$ \\
\hline M & 27 & 0.16 & US \& DXA & $\mathrm{T} 3$ & A \\
\hline M & 29 & 0.35 & US \& DXA & T6 & A \\
\hline $\mathrm{M}$ & 30 & 12.72 & US \& DXA & $\mathrm{C} 4$ & A \\
\hline $\mathrm{M}$ & 34 & 10.91 & US & C6 & $\mathrm{C}$ \\
\hline M & 34 & 16.98 & US \& DXA & T6 & B \\
\hline M & 35 & 0.50 & US & $\mathrm{C} 7$ & $\mathrm{D}$ \\
\hline M & 37 & 3.52 & US & T5 & A \\
\hline M & 45 & 7.27 & US \& DXA & L3 & $\mathrm{C}$ \\
\hline M & 48 & 11.39 & US & C6 & $\mathrm{D}$ \\
\hline M & 49 & 0.58 & US & $\mathrm{T} 3$ & A \\
\hline M & 56 & 12.04 & US & $\mathrm{T} 11$ & A \\
\hline M & 58 & 35.90 & US & $\mathrm{T} 12$ & $\mathrm{C}^{*}$ \\
\hline
\end{tabular}

Abbreviations: $\mathrm{M}=$ Male; $\mathrm{F}=$ Female; $\mathrm{R}=$ oestrogen replete or premenopausal; $\mathrm{P}=$ postmenopausal; $\mathrm{H}=$ on hormone replacement therapy; DXA = dual energy X-ray absorptiometry measurement; US = ultrasound measurement; *indicates flaccid paraplegia

determined by the use of Fourier Transform. ${ }^{8}$ SOS is a function of elasticity, and BUA may be related to bone structure. From SOS and BUA, an index termed 'stiffness' has been derived by the manufacturer of the ultrasound bone densitometer. This is not stiffness in the true biomechanical sense that indicates the stress/ strain relationship of a bone, but a derived index of bone defined by the manufacturer. ${ }^{9}$ 'Stiffness' is expressed as a percentage relative to the mean value for young normals and it derives approximately two thirds of its value from the mean of the BUA and one third from the mean of SOS measurements.

BUA, SOS and 'stiffness' have been found to correlate with the bone mineral density measurements and to give a clinical index of fracture risk in otherwise healthy populations. . $^{7,10,11}$

In this study, we have examined the ultrasonic properties of the calcaneus in a number of patients at various stages after spinal injury and have compared the relationship between ultrasonic measurements at the calcaneus with DXA measurements at the spine and proximal femur.

\section{Patients and methods}

Patients were attending the Midlands Centre for Spinal Injuries. Thirty-one spinal injury patients, 12 females and 19 males, were studied. Eleven patients were within 3 months of injury, seven patients were between 4 and 12 months after injury and 13 patients were more than 1 year since injury. Eight female patients were having regular periods, two were on hormone replacement therapy (HRT) and two were postmenopausal. Fourteen patients had suffered complete lesions. There were also 15 patients with incomplete lesions and two patients, in the acute stages of injury after fracture of the cervical spine, were neurologically intact (Frankel score E). Details of the patients are summarised in Table 1.

An Achilles (Lunar Corporation, Madison, WI, USA) ultrasound bone densitometer (USBD) was used to scan the right heel of all patients. Its use in normal populations has previously been described in detail. $^{12}$ In brief, measurement of the calcaneus requires the patient to sit on a chair with the right foot placed in a chamber, the lid acting as a calf support. Before placing the foot in the chamber, both sides of the heel are cleaned with alcohol to remove any surface debris that may interfere with the ultrasound measurement. The foot is positioned with a purpose-built toe-peg to aid reproducibility. Then water, preheated to $37^{\circ} \mathrm{C}$, enters the chamber surrounding the heel. Air bubbles in the water are minimised by a solution containing surfactant and an antimicrobial agent. The USBD consists of two $2.54 \mathrm{~cm}$ diameter, $500 \mathrm{KHz}$ unfocused transducers mounted coaxially $9.5 \mathrm{~cm}$ apart. Ultrasound signals transmitted from one transducer through the calcaneus, are received by the other transducer. The received ultrasound signals are digitised and stored in a portable IBM compatible computer for future analysis. Scanning takes about $5 \mathrm{~min}$. The co-efficient of variation $(\mathrm{CV})$ for the ultrasound measurements are: $\quad \mathrm{BUA}=1.38 \pm 0.45 \%, \quad \mathrm{SOS}=0.19 \pm 0.08 \% \quad$ and 'stiffness' $=1.49 \pm 0.59 \% .{ }^{12}$

Regional bone mineral DXA measurements at the lumbar spine (from L2 to L4) and the proximal femur were undertaken within 30 days of the ultrasound scan in 18 patients, using an Hologic QDR 1000/W densitometer. The average time interval between the USBD and DXA scans was $8.4 \pm 7.7$ days. In two patients $101 / 2$ and 17 weeks post injury, scans were undertaken 16 and 19 days apart. In a further two patients, 2.02 and 7.27 years post injury scans were separated by 27 and 16 days respectively. All other patients had both scans within 15 days. The specific sites at the proximal femur region (femoral neck, Ward's triangle, trochanteric and inter-trochanteric) were determined by the 
manufacturer's instructions (Hologic Inc., Waltham, MA, USA). The reproducibility of DXA measurement is $1.30 \%$ at the lumbar spine and $1.83 \%$ at the femoral neck. ${ }^{6}$

Ultrasound 'stiffness' values for a 'normal' reference population of 1933 women and 460 men were obtained from the manufacturer (Lunar Corporation). However the matching values for BUA and SOS from which this index was derived were not available to us.

Values for BUA and SOS reported in this paper were derived from a cohort of 79 healthy volunteers (15 men, 64 women (age range 18-77 years)) recruited from the local population.

Z-scores were calculated for 'stiffness' at the calcaneus, by comparing the value at the calcaneus of the patients with the 'stiffness' for the age and sex related reference population provided by the manufacturer. The percentage difference was calculated from the age and sex related reference population, according to the following equation

$$
\text { percentage difference in 'stiffness' }=\frac{S_{p}-S_{m} \times 100}{S_{m}}
$$

The $z$-score in 'stiffness' was calculated using the following equation

$$
\text { z-score in 'stiffness' }=\frac{S_{p}-S_{m}}{S_{d}}
$$

where:

$S_{p}=$ USBD 'stiffness' measurement of patient

$S_{m}=$ mean USBD 'stiffness' of the same age

group from the manufacturer's reference population

$S_{d}=$ standard deviation in 'stiffness' of the same age group from the manufacturer's reference popuation

Similarly, the z-scores and the percentage differences for female patients in BMD at the lumbar spine and the femoral neck were calculated by comparing the values of $\mathrm{BMD}$ at the lumbar spine and the femoral neck of the patients with the BMD for the age and sex matched reference population obtained from our longterm clinical study. ${ }^{6}$ Data for male patients were compared with our reference values for healthy male subjects (unpublished data). Table 2 summarises the reference BMD at the lumbar spine and the femoral neck in both healthy men and women. Men and women were recruited from the local population whose age ranged from 18 to 62 years. All subjects were screened with a questionnaire, serum osteocalcin, calcium, liver function and urine tests, and $24 \mathrm{~h}$ urinary hydroxyproline excretion. The women had a lateral radiograph of the dorsal and lumbar spine to ensure absence of vertebral fractures.

Results are expressed as mean \pm standard deviation (SD). Bivariate correlations were undertaken to examine the relationship of ultrasound properties at the calcaneus and DXA measurements at the lumbar spine and proximal femur (SPSS UK Ltd., Chertsey, UK). Comparisons between groups were tested with the Mann-Whitney U-Test.

\section{Results}

Values for 'stiffness' at the calcaneus and BMD at the lumbar spine and femoral neck region of the proximal femur, expressed in terms of z-scores and percentage differences, and partitioned into different groups according to time since injury are shown in Table 3.

\section{Ultrasound bone density measurements}

The z-scores and percentage differences in 'stiffness' at the calcaneus in all SCI patients were significantly lower $(P<0.05$ in all cases $)$ compared with the healthy reference population at all times after injury. Since stiffness is derived from BUA and SOS, the relationship between BUA and SOS at the calcaneus was examined in a group of our healthy subjects and in those patients with SCI. There was no evidence that patients with SCI at any time after injury exhibited a relationship between BUA and SOS that was significantly different from that of healthy subjects (Figure 1). Two patients with Frankel E grade who were measured within 3 months of injury, had a mean

\begin{tabular}{|c|c|c|c|c|c|c|c|c|c|c|}
\hline \multirow[b]{2}{*}{ Age } & \multirow[b]{2}{*}{$\mathrm{n}$} & \multicolumn{4}{|c|}{$\begin{array}{l}B M D \text { in healthy women }\left(\mathrm{g} / \mathrm{cm}^{2}\right) \\
\text { Lumbar Spine Femoral Neck }\end{array}$} & \multicolumn{4}{|c|}{$B M D$ in healthy men $\left(\mathrm{g} / \mathrm{cm}^{2}\right)$} & Neck \\
\hline & & Mean & $S D$ & Mean & $S D$ & $\mathrm{n}$ & Mean & $S D$ & Mean & $S D$ \\
\hline 20 & 10 & 1.07 & 0.08 & 0.90 & 0.10 & 16 & 1.07 & 0.13 & 1.02 & 0.16 \\
\hline 25 & 5 & 1.12 & 0.08 & 0.91 & 0.22 & 18 & 1.14 & 0.12 & 0.94 & 0.06 \\
\hline 30 & 9 & 1.14 & 0.12 & 0.87 & 0.04 & 16 & 1.03 & 0.1 & 0.87 & 0.11 \\
\hline 35 & 19 & 1.08 & 0.12 & 0.87 & 0.12 & 12 & 1.12 & 0.1 & 0.95 & 0.14 \\
\hline 40 & 41 & 1.07 & 0.14 & 0.84 & 0.10 & 14 & 1.08 & 0.15 & 0.89 & 0.12 \\
\hline 45 & 56 & 1.11 & 0.14 & 0.87 & 0.10 & 12 & 1.0 & 0.18 & 0.81 & 0.09 \\
\hline 50 & 55 & 1.04 & 0.13 & 0.80 & 0.09 & 22 & 1.11 & 0.16 & 0.9 & 0.13 \\
\hline 55 & 54 & 0.10 & 0.13 & 0.77 & 0.11 & 18 & 1.08 & 0.14 & 0.85 & 0.13 \\
\hline 60 & 59 & 0.96 & 0.18 & 0.76 & 0.11 & 19 & 1.05 & 0.15 & 0.84 & 0.11 \\
\hline
\end{tabular}

Table $2 \mathrm{BMD}$ at the lumbar spine and femoral neck region of the proximal femur in a healthy reference population 
'stiffness' $z$-score of -0.61 (range -0.24 to -0.97 ) which was not significantly different from other subjects with more severe Frankel grades.

There was no significant difference between the mean $\mathrm{z}$-score for 'stiffness' in female $-2.1 \pm 1.4$ and male $-1.5 \pm 1.3$ patients within the first year of injury.

Z-score for 'stiffness' was also compared in younger and older patients within 1 year since injury. Thirteen patients were under 35 years and five patients were over 35 years. The mean z-score for 'stiffness' was significantly lower $(P<0.05)$ in the older group $-2.8 \pm 1.1$ compared with the younger group $-1.3 \pm 1.3$. This suggests that the older patients lost more bone than the younger patients within the first year of injury.

\section{DXA bone density measurements}

No significant overall change in BMD occurred in the lumbar spine, although BMD decreased slightly between 3-12 months since injury and tended to increase after 12 months since injury. At the femoral neck the change in BMD was not significant up to 12 months. After 12 months there was a significant decline to a mean of 2.3 SDs below the reference population.

\section{Relationships between USBD and DXA}

Correlations were derived relating SOS, BUA and 'stiffness' at the calcaneus with values for BMD at different sites are summarised in Table 4. There was a negative correlation between ultrasound properties at the calcaneus and BMD at the lumbar spine, but positive relationships were found at sites in the proximal femur.

\section{Discussion}

The present work confirms that rapid bone loss takes place after spinal cord injury. Previous work comparing bone loss at the femur and at the tibia has suggested that bone loss may not be so rapid at proximal sites in the lower limb. In a longitudinal study, bone loss was more rapid at the tibial shaft than in the femoral shaft, ${ }^{3}$ whereas a cross-sectional study comparing bone loss either side of the knee joint indicated that rates of bone loss were similar at these two closely related anatomical sites. ${ }^{4}$ The present work extends these measurements to the calcaneus and establishes the site specific nature of both the initial rate of loss and of the final extent of bone loss. The present data show that bone loss from the calcaneus, during the first 3 months of injury, was more rapid when compared with the proximal femur (Table 3).

Prevention of bone mineral loss is becoming increasingly important in spinal injury patients. Improved rehabilitation and the development of equipment to aid walking requires the preservation of the mechanical integrity of the skeleton. Because of

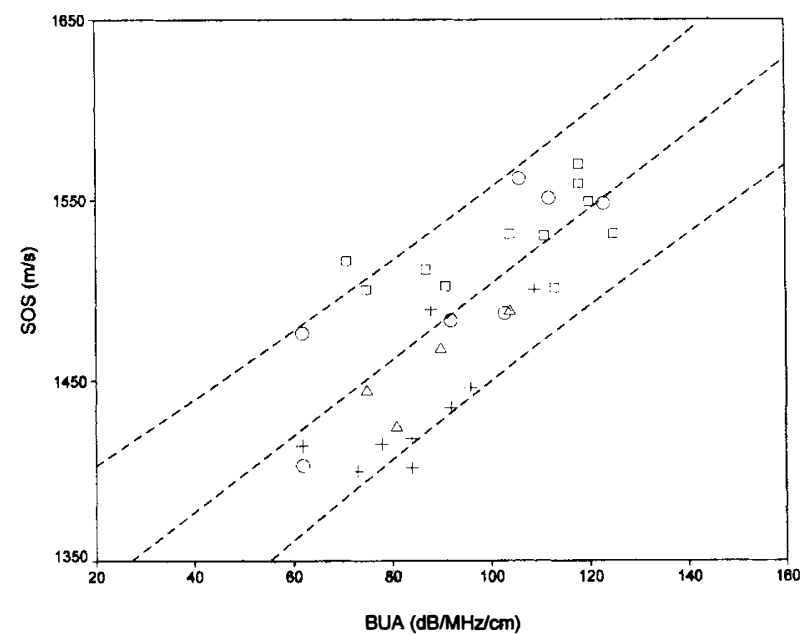

Figure 1 Relationship between BUA and SOS in four groups with different time since injury. Time since injury: + , after 54 months; $\triangle, 12$ to 54 months; $\bigcirc, 3$ to 12 months; $\square$, within 3 months; - - -, healthy reference (Linear regression line with $95 \%$ confidence limits)

Table 3 Summary of the z-scores and percentage differences in different time periods after SCI

\begin{tabular}{|c|c|c|c|c|c|c|}
\hline & $\begin{array}{c}\text { mean } \\
z \text {-score in } \\
L S \text { - } B M D\end{array}$ & $\begin{array}{c}\text { mean } \\
z \text {-score in } \\
F N \text { - BMD }\end{array}$ & $\begin{array}{c}\text { mean } z \text {-score in } \\
\text { 'stiffness' at } \\
\text { calcaneus }\end{array}$ & $\begin{array}{c}\text { mean \% } \\
\text { difference in } \\
\text { LS-BMD }\end{array}$ & $\begin{array}{c}\text { mean \% } \\
\text { difference in } \\
\text { FN-BMD }\end{array}$ & $\begin{array}{c}\text { mean \% difference } \\
\text { in 'stiffness, at } \\
\text { calcaneus }\end{array}$ \\
\hline \multicolumn{7}{|l|}{ Under 12 months of injury } \\
\hline $\begin{array}{l}\text { Within } 3 \text { months } \\
\text { of injury }\end{array}$ & $-0.2 \pm 1.1$ & $0.2 \pm 1.8$ & $-1.6 \pm 1.4^{* *}(11)$ & $-3.0 \pm 12.1$ & $-2.1 \pm 14.7$ & $-21.6 \pm 15.8^{* *}(11)$ \\
\hline $\begin{array}{l}3-12 \text { months } \\
\text { of injury }\end{array}$ & $-0.4 \pm 1.1$ & $-0.5 \pm 1.0$ & $-2.0 \pm 1.4^{*}$ & $-2.2 \pm 7.8$ & $-6.1 \pm 11.3$ & $-33.1 \pm 29.0^{*}$ \\
\hline \multicolumn{7}{|l|}{ Over 12 months of injury } \\
\hline $\begin{array}{l}12-54 \text { months } \\
\text { of injury }\end{array}$ & 0.3 & -2.4 & $-3.2 \pm 1.1^{*}$ & (1) & -28.0 & $-49.2 \pm 15.9^{*}$ \\
\hline $\begin{array}{l}\text { After } 54 \text { months } \\
\text { of injury }\end{array}$ & $1.7 \pm 1.0(4)$ & $-2.3 \pm 1.7^{*}(4)$ & $-3.3 \pm 1.4^{* *}$ & $20.8 \pm 11.3$ & $-29.1 \pm 22.2^{*}(4)$ & $-55.5 \pm 21.0^{* *}$ \\
\hline
\end{tabular}

Data are presented as mean $\pm \mathrm{SD}(\mathrm{n})$. * significance level compared with reference population $P<0.05 ; * *$ significance level compared with reference population $P<0.005$ where LS $=$ Lumbar spine; FN=Femoral neck; $\mathrm{n}=$ number of subjects 
Table 4 Summary of the correlation coefficients between the Ultrasonic properties and the BMD at different sites in 18 patients recorded

\begin{tabular}{lcccc}
\hline & & & 'stiffness' \\
& $\begin{array}{c}\text { BUA at } \\
\text { calcaneus calcaneus calcaneus }\end{array}$ \\
\hline BMD at Lumbar spine (L2-L4) & $-0.54^{*}$ & $-0.69^{* *}$ & $-0.67 * *$ \\
BMD at Ward's triangle & $0.69^{* *}$ & $0.74^{* *}$ & $0.77^{* *}$ \\
BMD at Femoral neck & $0.62^{* *}$ & $0.66^{* *}$ & $0.69^{* *}$ \\
BMD at Trochanter & 0.39 & $0.48^{*}$ & $0.47^{*}$ \\
BMD at Intertrochanter & $0.54^{*}$ & $0.63^{* *}$ & $0.64^{* *}$ \\
BMD at proximal femur & $0.53^{*}$ & $0.62^{* *}$ & $0.63^{* *}$ \\
\hline
\end{tabular}

${ }^{*}$ significance level $P<0.05 .{ }^{* *}$ significance level $P<0.005$

the speed with which loss occurs at the calcaneus, ultrasound methods appear to be promising as a means of assessing early bone loss.

The early and rapid loss at the calcaneus shows that any measure to prevent bone loss will be required as soon as possible after SCI. Ultrasound bone densitometry would appear to be a useful technique to monitor efficacy of therapy and may prove more versatile than most currently available DXA techniques.

Ultrasound measurement of calcaneal bone loss has emphasised the magnitude of the loss of mineral in the early weeks after injury. It is during this period that heterotopic bone is laid down in the trochanteric region. ${ }^{13}$ The present study did not investigate the relationship of these two events, but treatment possibly with bisphosphonates ${ }^{14,15}$ may not only prevent bone loss but also reduce the incidence of heterotopic calcification. The extent of final bone loss appears to relate to anatomical site, with those sites losing most bone being furthest from the spinal cord. Thus bone loss at the calcaneus is almost $55 \%$ by 54 months, compared with about $50 \%$ in the tibial shaft, ${ }^{3}$ $37 \%$ around the knee, ${ }^{4}$ and $29 \%$ in the femoral neck. The finding that bone density increased in the lumbar spine is not unexpected, ${ }^{16}$ and may be attributable to the weight bearing of the lumbar spine when the mobilised patient sits in a wheelchair.

Bone loss in the femoral neck may be ameliorated in postmenopausal women by oestrogen therapy. ${ }^{17}$ The presence of sex hormones may have some limiting effect since bone loss was more rapid in older subjects than in younger subjects, but nevertheless younger subjects still lost bone. One woman of postmenopausal age on hormone replacement therapy was not protected against bone loss, suggesting that oestrogens may not have a major role to play in bone loss through immobilisation. The present study demonstrates that the presence of oestrogen was no more effective than that of testosterone since premenopausal women lost bone as readily as men.

Relationships were also sought between ultrasound 'stiffness' values at the calcaneus and with DXA measurements at the lumbar spine and upper femur sites. There was generally reasonable agreement with speed of sound correlating better than BUA (Table 4). The correlations noted in healthy subjects between BUA at the calcaneus and DXA measurements at the femoral neck have ranged from $0.29-0.57$. $7,11-13$

Our values approximate to this range suggesting that bone density at the calcaneus is reflected in the bone mass at the femoral neck. Although rates of loss may differ, the relationship between the bone mass at the two sites does not appear to break down. It was also of some interest to investigate the relationship between BUA and SOS. This relationship is well described $^{11}$ and is maintained in osteoporosis. ${ }^{7}$ The correlation between BUA and SOS remained at all times after injury and all but two of the values were within the $95 \%$ confidence limits of the relationship found in our healthy subjects (Figure 1). In this limited number of patients, the relationship between BUA and SOS was maintained during periods of rapid bone loss.

Immobilisation can lead to a depletion in bone ${ }^{20-22}$ and it is uncertain whether the superimposed effect of nerve injury can accentuate the process. In two subjects who were neurologically intact (Frankel E), mean 'stiffness' z-score was not significantly different from more severe grades suggesting that immobilisation may be a major component of bone loss following SCI.

The present data show that ultrasound technology has the potential to fulfil an important role in the assessment of bone loss after spinal injury. Ultrasound bone densitometry is useful in patients with spinal injury because it requires the patient to remain still for a shorter time than does DXA. Spasm is therefore less of a problem and maintenance of position easier. Patient repositioning for longitudinal studies is also likely to be more reliable. It is also non-invasive and reveals both early and considerable changes in bone loss. Any form of therapy designed to prevent bone loss after spinal injury requires to be started immediately after injury and measurement of calcaneal bone mass will be an important adjunct to biochemical derangements, ${ }^{23,24}$ in assessing bone status after SCI.

\section{Acknowledgements}

The authors are grateful to AuRa Scientific Ltd. (Milton Ernest, UK) for the supply of the Achilles Ultrasound Bone Densitometer.

\section{References}

1 Claus-Walker J, Spencer WA, Carter RE, Halstead LS. Bone metabolism in quadriplegia: dissociation between calciuria and hydroxyprolinuria. Archives of Physical Medicine \& Rehabilitation 1975; 56: $327-332$.

2 Biering-Sørensen F, Bohr H, Schaadt OP. Bone mineral content of the lumbar spine and lower extremities years after spinal cord lesion. Paraplegia 1988; 26: 293 - 301 .

3 Biering-Sørensen F, Bohr HH, Schaadt OP. Longitudinal study of bone mineral content in the lumbar spine, the forearm and the lower extremities after spinal cord injury. Euro J Clin Invest 1990; 20: $330-335$. 
4 Garland DE et al. Osteoporosis after spinal cord injury. Journal of Orthopaedic Research 1992; 10: 371 - 378.

5 Ingram RR, Suman RK, Freeman PA. Lower limb fractures in the chronic spinal cord injured patient. Paraplegia 1989; 27: $133-$ 139.

6 Haddaway MJ, Davie MWJ, McCall IW. Bone mineral density in healthy normal women and reproducibility of measurements in spine and hip using dual energy X-ray absorptiometry. $\mathrm{Br} J$ Radiol 1992; 65: 213-217.

7 Herd RJ et al. Measurement of postmenopausal bone loss with a new contact ultrasound system. Calcif Tissue Int 1993; 53: 153 157.

8 Langton CM, Palmer SB, Porter RW. The measurement of broadband ultrasound attenuation in cancellous bone. Eng Med 1984; 13: 89-91.

9 Mautalen $\mathrm{C}$ et al. Ultrasound and dual X-ray absorptiometry densitometry in woman with hip fracture. Calcif Tissue Int 1995; 57: $165-168$.

10 Porter RW, Miller CG, Grainger D, Palmer SB. Prediction of hip fracture in elderly women: a prospective study. $\mathrm{Br}$ Med J 1990; 301: $638-641$.

11 Waud CE, Lew $\mathrm{R}$, Baren TD. The relationship between ultrasound and densitometric measurements of bone mass at the calcaneus in woman. Calcif Tissue Int 1992; 51: 415-418.

12 Lees B, Stevenson JC. Prelininary evaluation of a new ultrasound bone densitometer. Calcified Tissue Int 1993; 53: 149-152.

13 Cassar-Pullicino VN et al. Sonographic diagnosis of heterotopic bone formation in spinal injury patients. Paraplegia 1993; 31: 40 50.

14 Chappard D et al. Effect of tiludronate on bone loss in paraplegic patients. Journal of Bone and Mineral Research 1995; 10(1): 112 118.
15 Marshall MJ, Holt I, Davie MWJ. Normal and therapeutic regulation of bone resorption. J Orthop Res 1995; 8: 63-68.

16 Leslie WD, Nance PW. Dissociated hip and spine demineralisation: a specific finding in spinal cord injury. Arch Phys Med Rehabil 1993; 74: 960-964.

17 Evans SF, Davie MWJ. Low and conventional dose transdermal oestradiol are equally effective at preventing bone loss in spine and femur at all post-menopausal ages. Clin Endocrinol 1996; 44: $79-84$.

18 Salmone LM, Krall EA, Harris S, Dawson-Hughes B. Comparison of broadband ultrasound attenuation to single X-ray absorptiometry measurements at the calcaneus in postmenopausal women. Calcif Tissue Int 1993; 54: 87-90.

19 Palacios S, Menéndez C, Calderón J, Rubio S. Spine and femur density and broadband ultrasound attenuation of the calcaneus in normal spanish women. Calcif Tissue Int 1992; 52: 99-102.

20 Minaire $\mathrm{P}$ et al. Quantitative histological data on disuse osteoporosis: comparison with biological data. Calcif Tiss Res 1974; 17: $57-73$.

21 Uhthoff HK, Jaworski ZFG. Bone loss in response to long term immobilisation. J Bone Joint Surg 1978; 60B: 420-429.

22 Skerry TM, Lanyon LE. Immobilisation induced bone loss in sheep is not modulated by calcitonin treatment. Bone 1993; 14(3): $511-516$.

23 Sharp CA et al. Bone turnover after spinal cord injury. Bone 1995; 16: $186 \mathrm{~S}$.

24 Uebelhart D et al. Early modifications of biochemical markers of bone metabolism in spinal cord injury patients: a preliminary study. Scand J Rehab Med 1994; 26: 197-202. 